Article

\title{
The Influence of Nutritional Supplementation for Iron Deficiency Anemia on Pregnancies Associated with SARS-CoV-2 Infection
}

\author{
Mihaela Uta ${ }^{1}$, Radu Neamtu ${ }^{1, *(D)}$, Elena Bernad ${ }^{1}$, Adelina Geanina Mocanu ${ }^{1}$, Adrian Gluhovschi ${ }^{1}$, \\ Alin Popescu ${ }^{1}$, George Dahma ${ }^{1}$, Catalin Dumitru ${ }^{1}$, Lavinia Stelea ${ }^{1}$, Cosmin Citu ${ }^{1}$ (D), Felix Bratosin ${ }^{2} \mathbb{D}$ \\ and Marius Craina ${ }^{1}$
}

1 Discipline of Obstetrics and Gynecology, “Victor Babes” University of Medicine and Pharmacy, 300041 Timisoara, Romania; utamiha@yahoo.com (M.U.); ebernad@yahoo.com (E.B.); adelinaerimescu@yahoo.com (A.G.M.); adigluhovschi@yahoo.com (A.G.); alinp22@yahoo.com (A.P.); george_dahma@yahoo.com (G.D.); dumcatal@yahoo.com (C.D.); stelea_lavinia@yahoo.com (L.S.); citu.ioan@umft.ro (C.C.); crainamariuslucian@gmail.com (M.C.)

2 Methodological and Infectious Diseases Research Center, Department of Infectious Diseases,

"Victor Babes" University of Medicine and Pharmacy, 300041 Timisoara, Romania; felix.bratosin7@gmail.com

* Correspondence: radu.neamtu@umft.ro; Tel.: +40-729-098-886

check for updates

Citation: Uta, M.; Neamtu, R.; Bernad, E.; Mocanu, A.G.;

Gluhovschi, A.; Popescu, A.; Dahma, G.; Dumitru, C.; Stelea, L.; Citu, C.; et al. The Influence of Nutritional Supplementation for Iron Deficiency Anemia on Pregnancies Associated with SARS-CoV-2 Infection. Nutrients 2022, 14, 836. https://doi.org/ $10.3390 /$ nu14040836

Academic Editors: Annunziata Lapolla and Ewa WenderOzegowska

Received: 3 February 2022 Accepted: 14 February 2022 Published: 16 February 2022

Publisher's Note: MDPI stays neutral with regard to jurisdictional claims in published maps and institutional affiliations.

Copyright: (C) 2022 by the authors. Licensee MDPI, Basel, Switzerland. This article is an open access article distributed under the terms and conditions of the Creative Commons Attribution (CC BY) license (https:// creativecommons.org/licenses/by/ $4.0 /)$.

\begin{abstract}
Anemia is a very common occurrence during pregnancy, with important variations during each trimester. Anemia was also considered as a risk factor for severity and negative outcomes in patients with SARS-CoV-2 infection. As the COVID-19 pandemic poses a significant threat for pregnant women in terms of infection risk and access to care, we developed a study to determine the impact of nutritional supplementation for iron deficiency anemia in correlation with the status of SARS-CoV-2 infection. In a case-control design, we identified 446 pregnancies that matched our inclusion criteria from the hospital database. The cases and controls were stratified by SARS-CoV-2 infection history to observe the association between exposure and outcomes in both the mother and the newborn. A total of 95 pregnant women were diagnosed with COVID-19, having a significantly higher proportion of iron deficiency anemia. Low birth weight, prematurity, and lower APGAR scores were statistically more often occurring in the COVID-19 group. Birth weight showed a wide variation by nutritional supplementation during pregnancy. A daily combination of iron and folate was the optimal choice to normalize the weight at birth. The complete blood count and laboratory studies for iron deficiency showed significantly decreased levels in association with SARS-CoV-2 exposure. Puerperal infection, emergency c-section, and small for gestational age were strongly associated with anemia in patients with COVID-19. It is imperative to screen for iron and folate deficiency in pregnancies at risk for complications, and it is recommended to supplement the nutritional intake of these two to promote the normal development and growth of the newborn and avoid multiple complications during pregnancy in the COVID-19 pandemic setting.
\end{abstract}

Keywords: SARS-CoV-2; COVID-19; pregnancy; pregnant women; iron deficiency; anemia; nutritional supplementation

\section{Introduction}

According to the World Health Organization, more than 2 billion people worldwide suffer from iron deficiency, and more than $38 \%$ of pregnant women worldwide suffer from anemia during pregnancy [1]. Anemia affects only $20 \%$ of pregnancies in the United States due to intensive screening and empiric nutritional supplementation during pregnancy [2], but still, iron-deficiency anemia is the most frequent anemia of pregnancy and one of the most frequent complications during pregnancy in developed countries [3,4]. Moreover, other studies researching anemia in pregnancy discovered that $42 \%$ of randomly chosen 
non-anemic first trimester women were iron deficient using conventional transferrin saturation and serum ferritin cut-off values [5]; however, iron deficiency screening using serum ferritin testing is not regularly recommended in unselected pregnancies in the United States and the United Kingdom.

Iron deficiency is widespread, especially in women of childbearing age, and is mostly caused by menstrual blood loss and a lack of iron-rich foods consumed orally [6]. This problem is exacerbated during pregnancy. Women need iron and folate throughout pregnancy to satisfy their own demands and those of the growing fetus. The issue is that if pregnant women become lacking in certain nutrients, they will be unable to provide them to the fetus in appropriate amounts. Iron deficiency anemia is defined by a low serum ferritin level, typically $15 \mu \mathrm{g} / \mathrm{L}$. Additionally, a serum ferritin concentration of $30 \mu \mathrm{g} / \mathrm{L}$ suggests depleted iron reserves [7]. Fetal growth requires around 800-850 $\mathrm{mg}$ of iron [8]. Women who are already iron deficient and anemic throughout early pregnancy will exhaust residual iron reserves and become more anemic. In women who are not anemic but are iron deficient, continued depletion of iron reserves may result in anemia. Even women with adequate hemoglobin and iron reserves are at risk of developing an iron deficit later in pregnancy. Iron deficiency anemia is related to an increased risk of blood transfusion, preterm birth, cesarean delivery, and neonatal critical care unit hospitalization if present at delivery $[9,10]$. Low folate intake before conception raises the chance of neural tube abnormalities in the infant. Inadequate iron and folate levels in women may result in anemia, which makes women weary, dizzy, and more susceptible to infections, such as the SARS-CoV-2, during the ongoing pandemic. As such, iron supplementation is suggested if this problem is detected during pregnancy or after delivery, since it is related to unfavorable maternal and newborn outcomes [11]. Therefore, three possible ways to prevent and control the development of iron deficiency and iron deficiency anemia should be considered. These encompass dietary diversification, food fortification and individual oral iron supplementation, as the first line method [12]. Considering the gastrointestinal upset caused by iron supplementation, this can be administered every other day with similar efficiency [13].

The pandemic caused by SARS-CoV-2 had a dramatic influence on healthcare systems, social institutions, and the global economy [14]. The COVID-19 pandemic's detrimental impacts on maternal and perinatal health are not confined to the disease's direct morbidity and death. We expect that Romanian pregnant women who are left behind for prenatal monitoring and treatment as a result of the COVID-19 pandemic's limitations [15-18] would have worse pregnancy outcomes, as it was recently demonstrated in a global analysis concluding that maternal and fetal outcomes have deteriorated as a result of the COVID-19 pandemic, with an increase in maternal deaths, stillbirths, and maternal depression [19-22]. As growing concerns during the pandemic affect medical workers and mothers, we believe that anemia during pregnancy can be easily overlooked in these times, as much as it is still an understudied topic in correlation with COVID-19. Therefore, we aimed to identify potential unwanted outcomes of anemia during pregnancy that might be associated with maternal exposure to SARS-CoV-2 and determine the difference made by nutritional supplementation in these pregnancies.

\section{Materials and Methods}

Between 1 January 2020 and 1 January 2022, the current retrospective populationbased cohort research was conducted at a tertiary hospital in Timisoara, Romania, at the Department of Obstetrics and Gynecology affiliated with Timis County Emergency Clinical Hospital. The following criteria applied to pregnant women included in the study: (1) providing informed consent and agreeing to participate; (2) giving birth at our clinic to a live child or stillbirth; (3) having a history of pregnancy screening at our outpatient clinic, with at least one full blood workup; and (4) being tested for SARS-CoV-2 before or during hospitalization using the usual RT-PCR protocol. We eliminated 214 pregnant women with a follow-up history at the outpatient clinic who delivered in a private setting. 
Additionally, 109 pregnant women who gave birth in our clinic during the study period did not agree to be involved in this research. At the conclusion of the data collection, 351 pregnant women who tested negative for COVID-19 and 95 pregnant women who tested positive for COVID-19 satisfied the inclusion criteria.

Anemia during pregnancy was defined by international guidelines as a hemoglobin concentration $(\mathrm{Hb})$ of $11.0 \mathrm{~g} / \mathrm{dL}$ in the first trimester, $10.5 \mathrm{~g} / \mathrm{dL}$ in the second and third trimesters, and $10.0 \mathrm{~g} / \mathrm{dL}$ postpartum [23]. We also assessed the serum ferritin as an excellent measure of the body's iron storage, and its level during early pregnancy is typically a solid predictor of iron deficiency, having a reference range of 10 to $200 \mathrm{ng} / \mathrm{mL}$ in women [24]. Other variables that were of interest for this particular study comprised general maternal characteristics (age, gravidity, parity), maternal pregnancy complications, neonatal characteristics, a maternal full blood count, sideremia, transferrin, serum iron, total iron-binding capacity (TIBC), a neonatal full blood count, with the additional evaluation of direct and total bilirubin, birth weight, and neonatal complications (prematurity, neonatal death, congenital anomalies, RBC transfusions). Following the diagnosis of iron deficiency anemia and/or folate deficiency, all pregnant patients received a normal release iron supplement with a medium daily dose of iron between $30 \mathrm{mg}$ and less than $60 \mathrm{mg}$ elemental iron. Folic acid was administered in a dose of 400 to 600 micrograms according to the guidelines of the American College of Obstetricians and Gynecologists [25].

This case-control study was approved by the Local Committee of Ethics for Scientific Research of Timis County Emergency Clinical Hospital for the Obstetrics and Gynecology Department, operating under provisions of article 167 of the Law number 95 from 2006, art. 28, chapter VIII of order 904/2006 and with EU GCP Directives 2005/28/EC established at the International Conference on Harmonization of Technical Requirements for Registration of Pharmaceuticals for Human Use (ICH), and with the Declaration of Helsinki-Recommendations Guiding Medical Doctors in Biomedical Research Involving Human Subjects. The current study protocol received ethical approval on 9 December 2021, with approval number A79.

Using the IBM SPSS v.26 statistical software and MedCalc v.20, we analyzed clinical and laboratory data from obstetric patients with and without an associated COVID-19 infection, stratified by the presence of iron deficiency anemia. Normally distributed parametric data were reported as mean and standard deviation, using the student's t-test or the ANOVA test to test for statistical significance. Non-normal data, as defined by median and interquartile range, were analyzed with the Mann-Whitney U-test and Kruskal-Wallis analysis of variance. The Chi-square test and Fisher's exact test were used to compare proportions. The significance threshold was set for $\alpha=0.05$.

\section{Results}

The general characteristics of study participants presented in Table 1 identified several important differences between groups stratified by COVID-19 status during pregnancy. Anemia was more often present in pregnant mothers with a history of SARS-CoV-2 infection during pregnancy $(42.1 \%$ vs. $29.3 \%, p=0.018)$, and their nutritional supplementation differed significantly. For example, the proportion of pregnant mothers with COVID-19 who were self-medicated or medically prescribed iron and folate as daily supplements were statistically significantly higher than in the COVID-19 negative group $(81.1 \% \mathrm{vs} .70 .7 \%$, $p=0.009$ ). The biggest difference was observed in those who took a daily dose of both iron and folic acid (52.6\% vs. 33.9\%). It was observed that newborns of mothers with anemia were also more likely to have anemia. In this case, the stratification by COVID-19 status determined a significant difference in the number of newborns identified with anemia $(31.6 \%$ vs. $21.7 \%, p=0.043)$. Another divergence between the two study groups was the newborn birth weight and APGAR scores. Therefore, the birth weight and APGAR score were statistically lower in the newborns of mothers with COVID-19 $(p=0.027)$, respectively $(p=0.029)$. 
Table 1. General characteristics of pregnancies associated with SARS-CoV-2.

\begin{tabular}{|c|c|c|c|}
\hline Variables * & $\begin{array}{c}\text { COVID-19 Positive } \\
(n=95)\end{array}$ & $\begin{array}{l}\text { COVID-19 Negative } \\
\quad(n=351)\end{array}$ & $p$ \\
\hline \multicolumn{4}{|l|}{ Maternal characteristics } \\
\hline Age & & & 0.269 \\
\hline$<25$ & $8(8.4 \%)$ & $44(12.5 \%)$ & \\
\hline $25-34$ & $65(68.4 \%)$ & $247(70.4 \%)$ & \\
\hline$>34$ & $22(23.2 \%)$ & $60(17.1 \%)$ & \\
\hline Gravidity & & & 0.826 \\
\hline 1 & $49(51.6 \%)$ & $171(48.7 \%)$ & \\
\hline 2 & $29(30.5 \%)$ & $108(30.8 \%)$ & \\
\hline$\geq 3$ & $17(17.9 \%)$ & $72(20.5 \%)$ & \\
\hline Parity & & & 0.296 \\
\hline 1 & $56(58.9 \%)$ & $189(53.8 \%)$ & \\
\hline 2 & $32(33.7 \%)$ & $116(33.0 \%)$ & \\
\hline$\geq 3$ & $7(7.4 \%)$ & $46(13.1 \%)$ & \\
\hline \multicolumn{4}{|l|}{ Complications } \\
\hline Anemia & $40(42.1 \%)$ & $103(29.3 \%)$ & 0.018 \\
\hline Gestational hypertension & $4(4.2 \%)$ & $12(3.4 \%)$ & 0.712 \\
\hline Gestational diabetes mellitus & $5(5.3 \%)$ & $20(5.7 \%)$ & 0.870 \\
\hline PROM & $10(10.5 \%)$ & $22(6.3 \%)$ & 0.153 \\
\hline Nutritional supplementation & & & 0.009 \\
\hline No Iron/Folic Acid & $18(18.9 \%)$ & $92(26.2 \%)$ & \\
\hline Iron & $17(17.9 \%)$ & $98(27.9 \%)$ & \\
\hline Folic Acid & $10(10.6 \%)$ & $42(12.0 \%)$ & \\
\hline Iron and Folic Acid & $50(52.6 \%)$ & $119(33.9 \%)$ & \\
\hline \multirow{2}{*}{\multicolumn{4}{|c|}{ Neonatal characteristics }} \\
\hline & & & \\
\hline Anemia & $30(31.6 \%)$ & $76(21.7 \%)$ & 0.043 \\
\hline Puerperal infection & $7(7.4 \%)$ & $18(5.3 \%)$ & 0.399 \\
\hline Premature birth & $14(14.7 \%)$ & $28(7.9 \%)$ & 0.045 \\
\hline Malformations & $2(2.1 \%)$ & $6(1.7 \%)$ & 0.796 \\
\hline Birth weight & & & 0.027 \\
\hline$<1500 \mathrm{~g}$ & $4(4.2 \%)$ & $5(1.4 \%)$ & \\
\hline $1500-2500 \mathrm{~g}$ & $15(15.8 \%)$ & $31(8.8 \%)$ & \\
\hline$>2500 \mathrm{~g}$ & $76(80.0 \%)$ & $315(89.7 \%)$ & \\
\hline APGAR score & & & 0.029 \\
\hline$\geq 9$ & $75(78.8 \%)$ & $308(87.7 \%)$ & \\
\hline $7-8$ & $10(10.6 \%)$ & $29(8.3 \%)$ & \\
\hline$\leq 6$ & $10(10.6 \%)$ & $14(4.0 \%)$ & \\
\hline
\end{tabular}

By evaluating the newborns' birth weight by COVID-19 and no COVID-19 groups, we observed the lowest median value in the group of newborns from mothers with COVID-19 who did not take iron or folate supplements during pregnancy (median birth weight $=2590 \mathrm{~g}$ ). The highest median value of birth weight was observed in the group of newborns from mothers without a SARS-CoV-2 infection who followed a nutritional supplementation with iron and folate (median birth weight $=3340 \mathrm{~g}$ ), as seen in Figure 1 . There was a significant difference in data stratified by nutritional supplementation between groups ( $p=0.022)$ but not within groups $(p=0.094)$.

The laboratory profile of pregnant women with anemia indicated that SARS-CoV-2 infection is associated with worsening anemia (Table 2). We observed statistically significant differences between groups of COVID-19 positive and COVID-19 negative patients, where the red blood cell count, hemoglobin, ferritin, sideremia, transferrin saturation, and reticulocyte count were significantly lower in COVID-19 positive pregnant women with anemia. The white blood cell count and haptoglobin levels were significantly elevated in the COVID-19 positive group. 


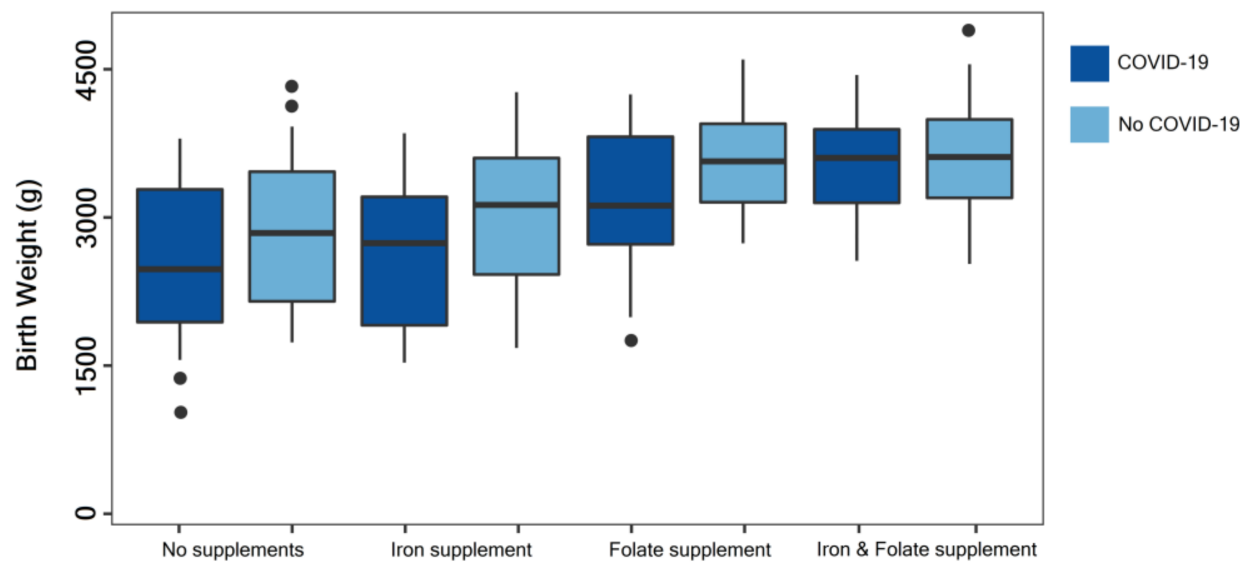

Figure 1. Boxplot comparison of birth weight by nutritional supplementation in newborns from COVID-19 positive vs. COVID-19 negative mothers. Data were stratified by nutritional supplements taken during pregnancy and evaluated using the Kruskal-Wallis test. Median values and interquartile range are represented inside the box; minimum, maximum, and outliers are shown outside the box as "•".

Table 2. Laboratory profile of pregnant women with iron deficiency anemia by the history of SARSCoV-2 infection.

\begin{tabular}{|c|c|c|c|c|}
\hline Laboratory Data * & Normal Range & $\begin{array}{c}\text { COVID-19 } \\
\text { Positive }(n=40)\end{array}$ & $\begin{array}{c}\text { COVID-19 } \\
\text { Negative }(n=103)\end{array}$ & $p$ \\
\hline RBC (millions $/ \mathrm{mm}^{3}$ ) & $4.0-5.0$ & $3.4 \pm 1.6$ & $3.8 \pm 1.2$ & 0.012 \\
\hline $\begin{array}{l}\text { Platelets } \\
\text { (thousands } / \mathrm{mm}^{3} \text { ) }\end{array}$ & $150-450$ & $168 \pm 31$ & $171 \pm 36$ & 0.643 \\
\hline WBC (thousands $/ \mathrm{mm}^{3}$ ) & $4.0-10.0$ & $12.6 \pm 4.8$ & $7.5 \pm 2.2$ & $<0.001$ \\
\hline Hemoglobin (g/dL) & $11.5-14.0$ & $10.1 \pm 2.9$ & $11.0 \pm 2.1$ & 0.041 \\
\hline Hematocrit $(\mathrm{g} / \mathrm{dL})$ & $35-44$ & $33.4 \pm 5.3$ & $34.7 \pm 4.6$ & 0.148 \\
\hline $\begin{array}{l}\text { Mean Corpuscular } \\
\text { Volume (fL) }\end{array}$ & $80-96$ & $88.7 \pm 9.5$ & $87.2 \pm 9.0$ & 0.379 \\
\hline Ferritin (ng/mL) & $30-150$ & $21.4 \pm 4.2$ & $23.3 \pm 4.6$ & 0.024 \\
\hline Sideremia $(\mu \mathrm{g} / \mathrm{dL})$ & $50-170$ & $42.8 \pm 6.2$ & $45.3 \pm 5.9$ & 0.026 \\
\hline Transferrin (saturation \%) & $15-45$ & $12.3 \pm 2.5$ & $13.8 \pm 2.0$ & $<0.001$ \\
\hline $\mathrm{Fe}(\mu \mathrm{mol} / \mathrm{L})$ & $10-30$ & $7.6 \pm 2.1$ & $8.8 \pm 2.3$ & 0.004 \\
\hline Reticulocyte count (\%) & $0.5-2.5$ & $0.6 \pm 0.2$ & $0.7 \pm 0.2$ & 0.008 \\
\hline Serum folate (nmol/L) & $10-45$ & $15.7 \pm 3.1$ & $16.2 \pm 3.0$ & 0.376 \\
\hline $\begin{array}{l}\text { Total iron-binding } \\
\text { capacity }(\mu \mathrm{g} / \mathrm{dL})\end{array}$ & $41-73$ & $68.0 \pm 9.1$ & $65.4 \pm 8.6$ & 0.112 \\
\hline Haptoglobin (g/L) & $0.3-2.0$ & $3.3 \pm 0.4$ & $0.5 \pm 0.1$ & $<0.001$ \\
\hline
\end{tabular}

Table 3 describes the comparison by the status of iron deficiency anemia between mothers infected with SARS-CoV-2 during pregnancy. It was observed that puerperal infections occurred in a statistically significantly higher proportion in mothers with anemia ( $52.5 \%$ vs. $27.3 \%, p=0.015)$. A total of $42.6 \%$ of pregnancies from mothers with COVID-19 and anemia terminated with emergency c-section, in comparison with $18.2 \%$ in the other group $(p=0.009)$. Additionally, the analysis found a significant difference in fetal growth, since $35.0 \%$ were small for gestational age in the group of pregnancies with anemia and SARS-CoV-2 infection, compared with $14.5 \%$ in pregnancies with SARS-CoV-2 infection but no anemia $(p=0.019)$. 
Table 3. Maternal and neonatal outcomes associated with SARS-CoV-2 infection stratified by presence of anemia.

\begin{tabular}{|c|c|c|c|c|}
\hline Variables * & Total $(n=95)$ & Anemia $(n=40)$ & No Anemia $(n=55)$ & $p$ \\
\hline \multicolumn{5}{|l|}{ Maternal outcomes } \\
\hline Severe COVID-19 & $5(5.3 \%)$ & $3(7.5 \%)$ & $2(3.6 \%)$ & 0.405 \\
\hline Puerperal infection & $7(26.3 \%)$ & $6(15.0 \%)$ & $1(1.8 \%)$ & 0.015 \\
\hline Postpartum hemorrhage & $18(18.9 \%)$ & $10(25.0 \%)$ & $8(14.5 \%)$ & 0.199 \\
\hline $\begin{array}{l}\text { Antepartum } \\
\text { hemorrhage }\end{array}$ & $18(18.9 \%)$ & $9(22.5 \%)$ & $9(16.4 \%)$ & 0.451 \\
\hline Transfusion necessity & $5(5.3 \%)$ & $4(10.0 \%)$ & $1(1.8 \%)$ & 0.077 \\
\hline Abnormal placentation & $9(9.5 \%)$ & $4(10.0 \%)$ & $5(9.1 \%)$ & 0.881 \\
\hline PROM ** & $10(10.5 \%)$ & $7(17.5 \%)$ & $3(5.4 \%)$ & 0.058 \\
\hline $\begin{array}{c}\text { Gestational } \\
\text { hypertension }\end{array}$ & $4(4.2 \%)$ & $3(7.5 \%)$ & $1(1.8 \%)$ & 0.173 \\
\hline $\begin{array}{c}\text { Gestational diabetes } \\
\text { mellitus }\end{array}$ & $5(5.3 \%)$ & $4(10.0 \%)$ & $1(1.8 \%)$ & 0.077 \\
\hline Pre-eclampsia & $4(4.2 \%)$ & $2(5.0 \%)$ & $2(3.6 \%)$ & 0.743 \\
\hline $\begin{array}{l}\text { Emergency c-section } \\
\text { Neonatal outcomes }\end{array}$ & $27(28.4 \%)$ & $17(42.6 \%)$ & $10(18.2 \%)$ & 0.009 \\
\hline Small for gestational age & $22(23.2 \%)$ & $14(35.0 \%)$ & $8(14.5 \%)$ & 0.019 \\
\hline Low birth weight & $19(20.0 \%)$ & $11(27.5 \%)$ & $8(14.5 \%)$ & 0.119 \\
\hline Prematurity & $14(14.7 \%)$ & $9(22.5 \%)$ & $5(9.1 \%)$ & 0.068 \\
\hline Sepsis & $5(5.3 \%)$ & $3(7.5 \%)$ & $2(3.6 \%)$ & 0.405 \\
\hline Low APGAR score $(<7)$ & $10(10.5 \%)$ & $6(15.0 \%)$ & $4(7.3 \%)$ & 0.225 \\
\hline
\end{tabular}

It was observed that newborn birth weight varied significantly by the status of maternal anemia $(n=40)$ in mothers who suffered a SARS-CoV-2 infection during pregnancy $(n=95)$. We observed the lowest median value in the group of newborns from mothers with anemia who did not take iron or folate supplements during pregnancy (median birth weight $=2410 \mathrm{~g}$ ). The highest median value of birth weight was observed in the group of newborns from mothers without anemia who followed a nutritional supplementation with iron and folate (median birth weight $=3480 \mathrm{~g}$ ), as seen in Figure 2. There was a significant difference between data stratified by nutritional supplementation between groups $(p<0.001)$ and within groups $(p=0.006)$.

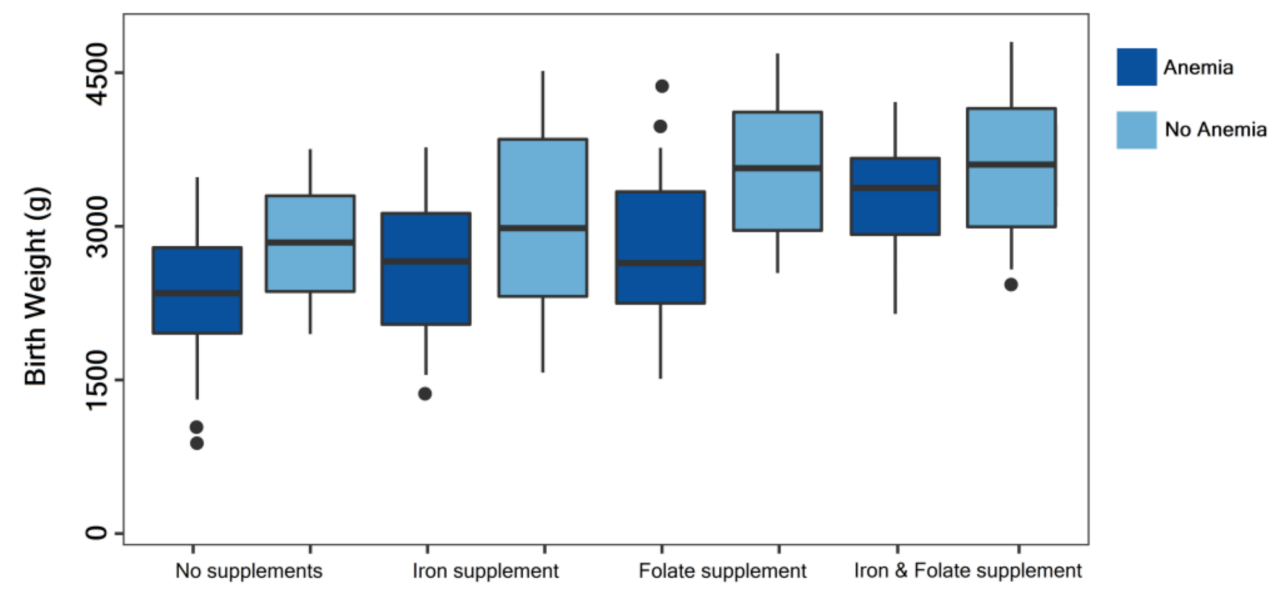

Figure 2. Boxplot comparison of birth weight in newborns from COVID-19 mothers with and without anemia. Data were stratified by nutritional supplements taken during pregnancy and evaluated using the Kruskal-Wallis test. Median values and interquartile range are represented inside the box; minimum, maximum, and outliers are shown outside the box as "•".

Lastly, the correlation analysis determined significant associations between maternal iron deficiency anemia and maternal and neonatal outcomes in both the COVID-19 positive 
and negative groups (Table 4). There was a significantly strong negative association between iron and folic acid supplementation with iron deficiency in COVID-19 positive pregnancies $(r=-0.646, p=0.005)$, and a lower negative association in pregnant women who followed an iron only nutritional supplementation $(r=-0.310, p=0.033)$. Anemia had a statistically significant positive correlation with severe SARS-CoV-2 infection, puerperal infection, transfusion necessity, emergency c-section, newborns small for gestational age. In the same manner, it was negatively correlated with birth weight and APGAR scores in COVID-19 positive mothers.

Table 4. Correlation of iron deficiency anemia with nutritional supplementation and pregnancy outcomes by COVID-19 status.

\begin{tabular}{ccccc}
\hline Variables * & \multicolumn{2}{c}{ COVID-19 Positive } & \multicolumn{2}{c}{ COVID-19 Negative } \\
\hline & $\boldsymbol{r}$ & $\boldsymbol{p}$ & $\boldsymbol{r}$ & $\boldsymbol{p}$ \\
Nutritional supplementation & & & & 0.204 \\
No Iron/Folic Acid & 0.229 & 0.148 & -0.248 & 0.127 \\
Iron & -0.310 & 0.033 & -0.255 & 0.202 \\
Folic Acid & -0.243 & 0.106 & -0.410 & 0.024 \\
Iron and Folic Acid & -0.646 & 0.005 & & \\
Maternal outcomes & & & - & - \\
Severe COVID-19 & 0.332 & 0.044 & 0.426 & 0.017 \\
Puerperal infection & 0.508 & 0.002 & 0.148 & 0.352 \\
Postpartum hemorrhage & 0.204 & 0.313 & 0.124 & 0.479 \\
Antepartum hemorrhage & 0.197 & 0.390 & 0.662 & 0.001 \\
Transfusion necessity & 0.691 & 0.001 & 0.347 & 0.320 \\
Abnormal placentation & 0.301 & 0.446 & 0.355 & 0.127 \\
PROM ** & 0.374 & 0.098 & 0.134 & 0.558 \\
Gestational hypertension & 0.126 & 0.670 & 0.128 & 0.643 \\
Gestational diabetes mellitus & 0.108 & 0.642 & 0.246 & 0.540 \\
Pre-eclampsia & 0.214 & 0.573 & 0.366 & 0.192 \\
Emergency c-section & 0.497 & 0.038 & & \\
Neonatal outcomes & & & 0.338 & 0.173 \\
Small for gestational age & 0.418 & 0.045 & -0.386 & 0.010 \\
Birth weight & -0.525 & 0.001 & 0.347 & 0.095 \\
Prematurity & 0.429 & 0.040 & 0.304 & 0.144 \\
Sepsis & 0.321 & 0.127 & -0.315 & 0.042 \\
APGAR score & -0.431 & 0.008 &
\end{tabular}

* Data reported as Spearman's correlation coefficient $(r)$ and probability ( $p$-value); ** Premature Rupture of Membranes.

\section{Discussion}

Our study sets an important step forward in understanding the implications of nutritional supplementation for iron deficiency anemia in pregnant women who suffered a SARS-CoV-2 infection during their pregnancy. This retrospective research allowed for comprehensive data collection of blood samples and clinical outcomes in the target population over a long time period. The primary merit of this study is represented by a comparison of laboratory profiles of pregnant women by the trimester of COVID-19 diagnosis to determine how SARS-CoV-2 is involved in existent alterations. Thus, we found evidence that anemia was more likely to be present in patients infected with SARS-CoV-2, and the severity of disease was higher in the pregnancies with a diagnosis of iron deficiency anemia. These findings are consistent with existing literature describing COVID-19 as a significant factor associated with anemia [26]. Another important consequence worth mentioning was the significantly lower birth weight of newborns from mothers with COVID-19 and anemia, even after adjusting for confounders.

\subsection{Review of the Literature}

Citing the existing literature, it is common that anemia in pregnancy is related to iron deficiency and there will always be increased strain on iron reserves as pregnancy 
continues. Pairing the complete blood count with serum ferritin minimizes the danger of iron supplementation in patients with probable iron excess indicated by high serum ferritin. Although tolerance and compliance are possible difficulties, employing a modest dosage is perhaps better tolerated. Starting early enhances the likelihood of having adequate storage later in pregnancy and seeks to limit the requirement for intravenous iron [27].

Anemia is also relatively prevalent comorbidity in patients with SARS-CoV-2 infection, occurring in about $25 \%$ of infected individuals, as a meta-analysis discovered [28]. More critically, individuals infected with SARS-CoV-2 who were anemic had a roughly 70\% increased risk of mortality in the near term compared to those who were not. Additionally, COVID-19 patients with hemoglobin higher than $10.0 \mathrm{~g} / \mathrm{dL}$ had a decreased risk of death than those with hemoglobin levels lower than 10/0 g/dL [29]. From a pathophysiological standpoint, hemoglobin concentration is a critical indicator of the blood's oxygen-carrying ability. As a result, anemia may further impair oxygen transport to peripheral tissue in COVID-19 patients with increased oxygen demand owing to pneumonia $[30,31]$.

In light of our findings, it is mandatory to cite the existing guidelines referring to the management of iron deficiency anemia during pregnancy, hoping that fewer complications will occur during the present pandemic and the future. Therefore, the Centers for Disease Control and Prevention and the World Health Organization recommend screening asymptomatic pregnant women for iron deficiency anemia using serum hemoglobin and ferritin levels, as well as universal iron supplementation with 30-60 mg/day of elemental iron during pregnancy [32,33]. They recommend increasing the amount of elemental iron to $60-120 \mathrm{mg} /$ day in pregnancies associated with anemia [34]. Despite iron pills being the most common type of supplementation, recent studies debate the use of lactoferrin in treating anemia in pregnant women [35], with potential benefits in the context of preventing and managing COVID-19 [36]. The Network for the Advancement of Patient Blood Management, Hemostasis, and Thrombosis consensus statement also recommends daily oral iron supplementation with $30-60 \mathrm{mg}$ /day in areas where there is a high prevalence of anemia during pregnancy and screening for iron deficiency in all pregnancies at risk of iron deficiency [37]. Additionally, the same consensus recommends intravenous iron in pregnancies associated with iron deficiency anemia and hemoglobin levels lower than $8.0 \mathrm{~g} / \mathrm{dL}$, or newly diagnosed iron deficiency anemia after 34 weeks of gestation [37]. Although by UK guidelines, intravenous iron is recommended in pregnancy if a woman is diagnosed with iron insufficiency after 34 weeks of gestation and has a hemoglobin level of $10.0 \mathrm{~g} / \mathrm{dL}$ or if she is intolerant to or does not respond to oral iron. In contrast, intravenous iron administration was not considered for our patients, nor is it a common approach in our country. Moreover, the United States Preventative Task Force notes a scarcity of data to justify widespread prenatal screening or iron supplementation, perhaps as a consequence of this uncertainty, fewer than a third of American obstetrician-gynecologists routinely supplement pregnant women with iron, which is similar to the situation that we are facing in Romania [38,39].

Although the necessity for blood transfusions was very low in our studied cohort, there was a significant increase in the group of patients with COVID-19 and anemia diagnosed during pregnancy. It is known that untreated anemia during pregnancy or at the time of birth increases the likelihood of having blood transfusions due to additional demands, such as blood loss [40]. Iron is administered intravenously, and blood is transfused in a hospital environment. This should be avoided in conditions caused by the COVID-19 pandemic, since it entails treatment in a hospital environment. A more proactive strategy is essential in light of the present pandemic situation. In view of the ongoing SARS-CoV-2 pandemic, one study suggests that all women with hemoglobin less than $12.0 \mathrm{~g} / \mathrm{dL}$ should have low-dose iron supplementation, even if their serum ferritin is normal [8]. The same study recommends that iron should also be supplied if the serum ferritin level is less than $30 \mathrm{mcg} / \mathrm{L}$, regardless of the hemoglobin level. This suggests that around $10 \%$ of pregnant women will be prescribed iron treatment solely based on their hemoglobin level at the time of evaluation. 


\subsection{Strengths and Limitations}

One limitation is the statistical power in comparing pregnant women with SARSCoV-2 infection by their status of anemia, since only 95 patients were included in the statistical analysis, and the incidence of complications was generally low. Furthermore, the study groups were not case-matched. Another limitation of the study can be the significant difference in nutritional supplementation that was found between groups of pregnant women with and without COVID-19. Here, we can consider the SARS-CoV-2 as a confounding factor that might influence the decision to take more supplements, hoping to recover faster and avoid unknown disease complications.

\section{Conclusions}

This study proved the importance of careful management and nutritional supplementation for iron deficiency anemia in pregnant women during the COVID-19 pandemic since the additive effect of SARS-CoV-2 infection on the impaired maternal health caused by anemia significantly increases the risks for negative outcomes for the mother and the newborn.

Author Contributions: Conceptualization, M.U. and R.N.; methodology, E.B., A.G.M. and M.C.; validation, A.P., G.D. and C.D.; formal analysis, L.S. and C.C.; investigation, F.B. and A.G.; resources, M.U.; data curation, R.N.; writing-original draft preparation, E.B. and A.G.M.; writing-review and editing, M.C., G.D. and A.P.; visualization, C.D. and L.S.; supervision, C.C. and F.B.; project administration, A.G. All authors have read and agreed to the published version of the manuscript.

Funding: This research received no external funding.

Institutional Review Board Statement: The Local Commission of Ethics for Scientific Research from the Timis County Emergency Clinical Hospital "Pius Brinzeu" from Timisoara, Romania operates under article 167 provisions of Law no. 95/2006, art. 28, chapter VIII of order 904/2006 and with EU GCP Directives 2005/28/EC, International Conference of Harmonisation of Technical Requirements for Registration of Pharmaceuticals for Human Use (ICH), and with the Declaration of HelsinkiRecommendations Guiding Medical Doctors in Biomedical Research Involving Human Subjects. The current study was approved on 9 December 2021, with the approval number A79.

Informed Consent Statement: Informed consent was obtained from all subjects involved in the study.

Data Availability Statement: The data presented in this study are available on request from the corresponding author.

Conflicts of Interest: The authors declare no conflict of interest.

\section{References}

1. Lewkowitz, A.K.; Gupta, A.; Simon, L.; Sabol, B.A.; Stoll, C.; Cooke, E.; Rampersad, R.A.; Tuuli, M.G. Intravenous compared with oral iron for the treatment of iron-deficiency anemia in pregnancy: A systematic review and meta-analysis. J. Perinatol. 2019, 39, 519-532. [CrossRef]

2. American College of Obstetricians and Gynecologists' Committee on Practice Bulletins-Obstetrics. Anemia in Pregnancy: ACOG Practice Bulletin, Number 233. Obstet. Gynecol. 2021, 138, e55-e64. [CrossRef] [PubMed]

3. James, A.H. Iron Deficiency Anemia in Pregnancy. Obstet. Gynecol. 2021, 138, 663-674. [CrossRef] [PubMed]

4. Turawa, E.; Awotiwon, O.; Dhansay, M.A.; Cois, A.; Labadarios, D.; Bradshaw, D.; Wyk, V.P.-V. Prevalence of Anaemia, Iron Deficiency, and Iron Deficiency Anaemia in Women of Reproductive Age and Children under 5 Years of Age in South Africa (1997-2021): A Systematic Review. Int. J. Environ. Res. Public Health 2021, 18, 12799. [CrossRef] [PubMed]

5. Auerbach, M.; Abernathy, J.; Juul, S.; Short, V.; Derman, R. Prevalence of iron deficiency in first trimester, non-anemic pregnant women. J. Matern. Fetal Neonatal Med. 2021, 34, 1002-1005. [CrossRef]

6. Coad, J.; Conlon, C. Iron deficiency in women. Curr. Opin. Clin. Nutr. Metab. Care 2011, 14, 625-634. [CrossRef] [PubMed]

7. Loy, S.L.; Lim, L.M.; Chan, S.-Y.; Tan, P.T.; Chee, Y.L.; Quah, P.L.; Chan, J.K.Y.; Tan, K.H.; Yap, F.; Godfrey, K.M.; et al. Iron status and risk factors of iron deficiency among pregnant women in Singapore: A cross-sectional study. BMC Public Health 2019, $19,397$. [CrossRef] [PubMed]

8. Stewart, T.; Lambourne, J.; Thorp-Jones, D.; Thomas, D. Implementation of early management of iron deficiency in pregnancy during the SARS-CoV-2 pandemic. Eur. J. Obstet. Gynecol. Reprod. Biol. 2020, 258, 60-62. [CrossRef] 
9. Vandermeulen, H.; Strauss, R.; Lin, Y.; McLeod, A.; Barrett, J.; Sholzberg, M.; Callum, J. The contribution of iron deficiency to the risk of peripartum transfusion: A retrospective case control study. BMC Pregnancy Childbirth 2020, 20, 196. [CrossRef] [PubMed]

10. Moreno-Fernandez, J.; Ochoa, J.J.; Latunde-Dada, G.O.; Diaz-Castro, J. Iron Deficiency and Iron Homeostasis in Low Birth Weight Preterm Infants: A Systematic Review. Nutrients 2019, 11, 1090. [CrossRef]

11. Abu-Ouf, N.M.; Jan, M.M. The impact of maternal iron deficiency and iron deficiency anemia on child's health. Saudi Med. J. 2015, 36, 146-149. [CrossRef] [PubMed]

12. Garzon, S.; Cacciato, P.M.; Certelli, C.; Salvaggio, C.; Magliarditi, M.; Rizzo, G. Iron Deficiency Anemia in Pregnancy: Novel Approaches for an Old Problem. Oman Med. J. 2020, 35, e166. [CrossRef]

13. Karakoc, G.; Orgul, G.; Sahin, D.; Yucel, A. Is every other day iron supplementation effective for the treatment of the iron deficiency anemia in pregnancy? J. Matern. Neonatal Med. 2021, 35, 832-836. [CrossRef] [PubMed]

14. Gill, S.; Adenan, A.M.; Ali, A.; Ismail, N.A.S. Living through the COVID-19 Pandemic: Impact and Lessons on Dietary Behavior and Physical Well-Being. Int. J. Environ. Res. Public Health 2022, 19, 642. [CrossRef] [PubMed]

15. Suwalska, J.; Napierała, M.; Bogdański, P.; Łojko, D.; Wszołek, K.; Suchowiak, S.; Suwalska, A. Perinatal Mental Health during COVID-19 Pandemic: An Integrative Review and Implications for Clinical Practice. J. Clin. Med. 2021, 10, 2406. [CrossRef]

16. Citu, C.; Neamtu, R.; Sorop, V.-B.; Horhat, D.I.; Gorun, F.; Tudorache, E.; Gorun, O.M.; Boarta, A.; Tuta-Sas, I.; Citu, I.M. Assessing SARS-CoV-2 Vertical Transmission and Neonatal Complications. J. Clin. Med. 2021, 10, 5253. [CrossRef] [PubMed]

17. Mazur-Bialy, A.I.; Kołomańska-Bogucka, D.; Tim, S.; Opławski, M. Pregnancy and Childbirth in the COVID-19 Era-The Course of Disease and Maternal-Fetal Transmission. J. Clin. Med. 2020, 9, 3749. [CrossRef]

18. Citu, C.; Gorun, F.; Motoc, A.; Sas, I.; Gorun, O.M.; Burlea, B.; Tuta-Sas, I.; Tomescu, L.; Neamtu, R.; Malita, D.; et al. The Predictive Role of NLR, d-NLR, MLR, and SIRI in COVID-19 Mortality. Diagnostics 2022, 12, 122. [CrossRef]

19. Chmielewska, B.; Barratt, I.; Townsend, R.; Kalafat, E.; van der Meulen, J.; Gurol-Urganci, I.; O’Brien, P.; Morris, E.; Draycott, T.; Thangaratinam, S.; et al. Effects of the COVID-19 pandemic on maternal and perinatal outcomes: A systematic review and meta-analysis. Lancet Glob. Health 2021, 9, e759-e772. [CrossRef]

20. Timircan, M.; Bratosin, F.; Vidican, I.; Suciu, O.; Tirnea, L.; Avram, V.; Marincu, I. Exploring Pregnancy Outcomes Associated with SARS-CoV-2 Infection. Medicina 2021, 57, 796. [CrossRef]

21. Citu, C.; Gorun, F.; Motoc, A.; Sas, I.; Gorun, O.M.; Burlea, B.; Serban, D.M.; Neamtu, R.; Citu, I.M. Hysteroscopy as a Primary Tool in Exploration and Treatment of Infertility: Single Center Experience in Western Romania. Diagnostics 2021, 11, 1917. [CrossRef] [PubMed]

22. Timircan, M.; Bratosin, F.; Vidican, I.; Suciu, O.; Turaiche, M.; Bota, A.V.; Mitrescu, S.; Marincu, I. Coping Strategies and Health-Related Quality of Life in Pregnant Women with SARS-CoV-2 Infection. Medicina 2021, 57, 1113. [CrossRef] [PubMed]

23. Pavord, S.; Myers, B.; Robinson, S.; Allard, S.; Strong, J.; Oppenheimer, C.; on behalf of the British Committee for Standards in Haematology. UK guidelines on the management of iron deficiency in pregnancy. Br. J. Haematol. 2012, 156, 588-600. [CrossRef] [PubMed]

24. Wang, W.; Knovich, M.A.; Coffman, L.G.; Torti, F.M.; Torti, S.V. Serum ferritin: Past, present and future. Biochim. Biophys. Acta (BBA) Gen. Subj. 2010, 1800, 760-769. [CrossRef] [PubMed]

25. Hanson, M.A.; Bardsley, A.; De-Regil, L.M.; Moore, S.E.; Oken, E.; Poston, L.; Ma, R.; McAuliffe, F.M.; Maleta, K.; Purandare, C.N.; et al. The International Federation of Gynecology and Obstetrics (FIGO) recommendations on adolescent, preconception, and maternal nutrition: “Think Nutrition First". Int. J. Gynecol. Obstet. 2015, 131, S213-S253. [CrossRef]

26. Bergamaschi, G.; de Andreis, F.B.; Aronico, N.; Lenti, M.V.; Barteselli, C.; Merli, S.; Pellegrino, I.; Coppola, L.; Cremonte, E.M.; Croce, G.; et al. Anemia in patients with Covid-19: Pathogenesis and clinical significance. Clin. Exp. Med. 2021, 21, 239-246. [CrossRef]

27. Moretti, D.; Goede, J.S.; Zeder, C.; Jiskra, M.; Chatzinakou, V.; Tjalsma, H.; Melse-Boonstra, A.; Brittenham, G.; Swinkels, D.W.; Zimmermann, M.B. Oral iron supplements increase hepcidin and decrease iron absorption from daily or twice-daily doses in iron-depleted young women. Blood 2015, 126, 1981-1989. [CrossRef]

28. Zuin, M.; Rigatelli, G.; Quadretti, L.; Fogato, L.; Zuliani, G.; Roncon, L. Prognostic Role of Anemia in COVID-19 Patients: A Meta-Analysis. Infect. Dis. Rep. 2021, 13, 930-937. [CrossRef]

29. Al-Jarallah, M.; Rajan, R.; Al Saber, A.; Pan, J.; Al-Sultan, A.T.; Abdelnaby, H.; Alroomi, M.; Dashti, R.; Aboelhassan, W.; Almutairi, F.; et al. In-hospital mortality in SARS-CoV-2 stratified by hemoglobin levels: A retrospective study. eJHaem 2021, 2, 335-339. [CrossRef]

30. Bonnesen, B.; Jensen, J.-U.S.; Jeschke, K.N.; Mathioudakis, A.G.; Corlateanu, A.; Hansen, E.F.; Weinreich, U.M.; Hilberg, O.; Sivapalan, P. Management of COVID-19-Associated Acute Respiratory Failure with Alternatives to Invasive Mechanical Ventilation: High-Flow Oxygen, Continuous Positive Airway Pressure, and Noninvasive Ventilation. Diagnostics 2021, 11, 2259. [CrossRef]

31. Covali, R.; Socolov, D.; Socolov, R.; Pavaleanu, I.; Carauleanu, A.; Akad, M.; Boiculese, V.L.; Adam, A.M. Complete Blood Count Peculiarities in Pregnant SARS-CoV-2-Infected Patients at Term: A Cohort Study. Diagnostics 2021, 12, 80. [CrossRef]

32. Centers for Disease Control and Prevention. Recommendations to prevent and control iron deficiency in the United States. MMWR Recomm. Rep. 1998, 47, 1-29. 
33. World Health Organization. Guideline: Daily Iron and Folic Acid Supplementation in Pregnant Women. Available online: http:/ / repository.poltekkes-kaltim.ac.id/1183/1/22.\%20Dairy\%20iron\%20and\%20folic\%20acid\%20supplementation\% 20in\%20pregnant\%20women.pdf (accessed on 6 January 2022).

34. Stoffel, N.U.; von Siebenthal, H.K.; Moretti, D.; Zimmermann, M.B. Oral iron supplementation in iron-deficient women: How much and how often? Mol. Asp. Med. 2020, 75, 100865. [CrossRef] [PubMed]

35. Lepanto, M.S.; Rosa, L.; Cutone, A.; Conte, M.P.; Paesano, R.; Valenti, P. Efficacy of Lactoferrin Oral Administration in the Treatment of Anemia and Anemia of Inflammation in Pregnant and Non-pregnant Women: An Interventional Study. Front. Immunol. 2018, 9, 2123. [CrossRef]

36. Sinopoli, A.; Isonne, C.; Santoro, M.M.; Baccolini, V. The effects of orally administered lactoferrin in the prevention and management of viral infections: A systematic review. Rev. Med. Virol. 2021, 32, e2261. [CrossRef]

37. Muñoz, M.; Peña-Rosas, J.P.; Robinson, S.; Milman, N.; Holzgreve, W.; Breymann, C.; Goffinet, F.; Nizard, J.; Christory, F.; Samama, C.-M.; et al. Patient blood management in obstetrics: Management of anaemia and haematinic deficiencies in pregnancy and in the post-partum period: NATA consensus statement. Transfus. Med. 2017, 28, 22-39. [CrossRef] [PubMed]

38. Kemper, A.R.; Fan, T.; Grossman, D.C.; Phipps, M.G. Gaps in evidence regarding iron deficiency anemia in pregnant women and young children: Summary of US Preventive Services Task Force recommendations. Am. J. Clin. Nutr. 2017, 106 (Suppl. 6), 1555S-1558S. [CrossRef]

39. Marcewicz, L.H.; Anderson, B.L.; Byams, V.R.; Grant, A.M.; Schulkin, J. Screening and Treatment for Iron Deficiency Anemia in Women: Results of a Survey of Obstetrician-Gynecologists. Matern. Child Health J. 2017, 21, 1627-1633. [CrossRef]

40. Scholz, R.; Young, D.; Scavone, B.; Hofer, J.; Siddiqui, M. Anemia in Pregnancy and Risk of Blood Transfusion [11C]. Obstet. Gynecol. 2018, 131, 33S. [CrossRef] 